\title{
Perceived Racial Discrimination and Mental Health in Diverse Groups of Asian Americans: The Differing Impacts by Age, Education, and Ethnicity
}

\author{
Yong Ju Cho ${ }^{1,2} \cdot$ Woo Jung Lee ${ }^{2} \cdot{\text { Hans } \mathrm{Oh}^{2} \cdot \text { Jungeun Olivia Lee }}^{2} \cdot$ Bo-Kyung Elizabeth $\mathrm{Kim}^{2} \cdot$ Yuri Jang ${ }^{1,2}$ (])
}

Accepted: 9 September 2021 / Published online: 20 September 2021

(c) The Author(s), under exclusive licence to Springer Science+Business Media, LLC, part of Springer Nature 2021

\begin{abstract}
The aim of this study was to examine how perceived racial discrimination is associated with mental distress among diverse Asian Americans and to explore the potential moderators in the relationship. Based on the 2015 Asian American Quality of Life (AAQoL) survey $(n=2609)$, direct influences were tested of the contextual (demographic, health-related, and immigration-related) variables and perceived racial discrimination on mental distress, as well as their interactions. About 30\% of the sample reported perceived racial discrimination, and $44 \%$ fell into the category of having mental distress. Perceived racial discrimination was associated with 1.90 times higher odds of mental distress and had significant interactions with age, education, and ethnicity. The association of mental distress with perceived racial discrimination was higher among those who were 60 or older, less educated, and Vietnamese than among their respective counterparts. Findings can guide strategic and targeted interventions for high-risk groups.
\end{abstract}

Keywords Perceived racial discrimination · Mental distress · Asian Americans · Unfair treatment

\section{Introduction}

Racial discrimination continues to be a persistent and ubiquitous social determinant of health that impacts people of color, including Asian Americans. Being regarded as "model minorities," Asian Americans often struggle to contend with this stereotype while still facing racial discrimination [1]. A substantial proportion (32-35\%) of Asian Americans report facing individual forms of discrimination such as racial slurs or comments about their racial background [2], and since the COVID-19 pandemic, many report their incidents of racial discrimination have escalated [3].

A sizable body of literature has identified racial discrimination as a major life stressor in diverse groups of racial and ethnic minorities [4]. The experience of discrimination,

Yuri Jang

yurij@usc.edu

1 Edward R. Roybal Institute on Aging, University of Southern California, 669 West 34th Street, Los Angeles, CA 90089-0411, USA

2 Suzanne Dworak-Peck School of Social Work, University of Southern California, 669 West 34th Street, Los Angeles, CA 90089-0411, USA including one based on race, has widely known associations with adverse mental health outcomes such as depression, anxiety, other psychological distress, and suicidality [4-6], and this association has been true for Asian Americans [7-14], though more research is needed about within-group differences. Having emigrated from more than 20 different countries of origin, each Asian American ethnic group possesses its own distinct cultures, languages, and socioeconomic status [15], resulting in different exposure and response to discriminatory experiences. However, studies with Asian Americans often conflate all Asian ethnicities into a single monolithic category $[3,6]$ or focus on a specific ethnic subgroup $[9,11]$, without close attention to intragroup differences.

In the present investigation with diverse ethnic subgroups of Asian Americans, we paid particular attention to the contextual factors that can shape the linkage between perceived racial discrimination and mental health. In the literature on stress and perceived discrimination, many researchers investigated the stress-buffering role of psychosocial resources such as ethnic identity, social support, cultural beliefs, and coping styles in Asian Americans [11-13]. Although these studies contribute to understanding the psychosocial mechanisms of perceived discrimination, there is a need to explore 
how the mental health consequences of discrimination differ by sociodemographic characteristics and health- and immigration-related profiles. Given the linkages of discriminatory experiences with contextual factors such as age, income, or education $[9,14,16]$, it is important to examine how they shape the impact of discrimination on the mental health of Asian Americans. Understanding the moderating effects of these contextual factors will enable identifying individuals at particular mental health risk and increase capacity to tailor intervention strategies.

The contextual factors we included in the present investigation are demographic characteristics (age, gender, marital status, education, and ethnicity), a physical health indicator (chronic medical conditions), and immigration-related variables (length of stay in the U.S., English speaking ability, and acculturation) selected based on the literature on perceived discrimination and immigrant mental health [9-14]. Hypothesizing that the mental health consequences of perceived racial discrimination would differ by demographic, health-related, and immigration-related characteristics, we examined (1) the direct effect of perceived racial discrimination on mental health and (2) the moderating effects of the contextual factors in the relationship between perceived racial discrimination and mental health.

\section{Methods}

\section{Data}

To gather concrete data on the rapid expansion of the Asian American population in the Austin area, the City of Austin conducted the Asian American Quality of Life (AAQoL) survey in 2015 [17]. The survey was administered to individuals aged 18 or older who self-identified as Asian Americans and who lived in Austin, Texas. The AAQoL survey questionnaires initially develped in English were translated into the native languages of five major Asian groups (e.g., traditional and simplified versions of Chinese, Hindi, Gujarati, Korean, Vietnamese, and Tagalog). They were given in a paper-and-pencil format, and participants chose their preferred language. To increase the diversity of the Asian American sample, we selected a total of 76 sites including churches, temples, grocery stores, and cultural events. The 10-page survey questionnaires were self-administered; however, bilingual and bicultural assistants were at the sites to help participants complete the surveys. The project was approved by the University of Texas at Austin Institutional Review Board. After we removed cases with more than $10 \%$ missing information, the final sample size decreased from 2614 to 2609 . Full details on the sample and the survey process and method can be accessed elsewhere [17].

\section{Measures}

\section{Mental Distress}

We assessed mental health with the Kessler Psychological Distress Scale-6 (K6), six questions that ask respondents if they feel nervous, hopeless, restless, depressed, everything was an effort, and worthless $[18,19]$. Each item was rated on a 5-point scale from 0 (none of the time) to 4 (all of the time), and total score could range from 0 to 24 (Cronbach's $\alpha=0.88$ in the overall sample, ethnic subgroup range: $0.87-0.90)$. Using the suggested cutoff, total scores were dichotomized $(\mathrm{K} 6<6=$ no mental distress, $\mathrm{K} 6 \geq 6=$ mental distress).

\section{Perceived Racial Discrimination}

Participants were asked to indicate if they had ever experienced discrimination or unfair treatment based on their race or ethnicity as a binary response $(0=$ no, $1=$ yes $)$.

\section{Demographic Characteristics}

Sociodemographic background information included age $(0=18-39,1=40-59,2=60$ or older $)$, gender $(0=$ male, $1=$ female $)$, marital status $(0=$ married, $1=$ not married $)$, education $(0=>12$ years, $1=\leq 12$ years $)$, and ethnicity $(0=$ Chinese, $1=$ Asian Indian, $2=$ Korean, $3=$ Vietnamese, $4=$ Filipino, $5=$ Other Asian). Of note, although age 65 is conventionally used for the lower end of the old age group, we used 60 based on the Asian customs that celebrate it as the start of a new cycle of life [20].

\section{Physical Health Indicator}

We measured chronic medical conditions with a question asking if a doctor had ever told participants having each of the following ten conditions (hypertension, heart disease, stroke, diabetes, cancer, arthritis, hepatitis, kidney problem, asthma, and chronic obstructive pulmonary disease). Total counts were recoded into three categories $(0=$ none, $1=$ one, $2=$ two or more).

\section{Immigration-Related Variable}

Length of stay in the U.S. was dichotomized into 0 (10 years or more) or 1 (less than 10 years) because we consider the 10 th year of residency as a marker of adaptation [21]. English speaking ability was rated on a 4-point scale, and we recoded this variable to be binary as categorizing those who spoke English less than "very well" as a group with limited 
English proficiency $(0=$ English proficient, $1=$ limited English proficiency). We assessed acculturation by asking respondents to rate their level of familiarity with the culture and customs of mainstream America on a 4-point scale, and we dichotomized that variable $(0=$ very high/high, $1=$ low/ very low).

\section{Analytic Strategies}

First, we examined the descriptive characteristics of the overall sample and ethnic subgroups. Ethnic group differences were evaluated by using Chi-square analyses. Prior to the main analyses, we calculated Spearman's correlations among the study variables to understand their underlying associations and ensure the absence of collinearity. Then, we tested logistic regression models of mental distress in a hierarchical manner with the following entry order: (1) demographic, health-related, and immigration-related contextual variables, (2) perceived racial discrimination, and (3) interactions between perceived racial discrimination and contextual variables. There were nine possible sets of interaction terms, and each was entered separately. For the significant interaction, we conducted subsequent analyses by stratifying the sample by a given moderating factor. For the multiple categories of ethnicity, we used Chinese as a reference group because they represent the largest and most studied Asian subgroup [8, 15]. We conducted all analyses using IBM SPSS Statistics 27.

\section{Results}

Table 1 summarizes the descriptive characteristics of the overall sample and the ethnic subgroups. Over $30 \%$ of the overall sample perceived racial discrimination, with the highest prevalence in Koreans (36.4\%) and the lowest in Asian Indians (18.9\%). More than $44 \%$ of the sample fell into the category of mental distress, with the highest prevalence among Vietnamese participants (54.6\%) followed by other Asians (48.9\%) and Koreans (43.8\%). We found statistically significant differences among the Asian American subgroups for all study variables, and Spearman's correlations showed that all study variables were associated with one another in an expected direction (not presented in tabular format). The highest correlation coefficient observed in the overall sample was between age and chronic medical conditions $\left(r_{s}=.45, p<.001\right)$, and there was no concern about collinearity.

Table 2 summarizes a series of logistic regression models for mental distress. In the initial model with the contextual variables only (Model 1), higher odds of mental distress were associated with younger age, unmarried status, more chronic medical conditions, and limited English proficiency.
By ethnicity, Koreans, Vietnamese, and those with other ethnicities showed 1.41-1.97 times higher odds of mental distress than Chinese. For Model 2, we added racial discriminatory experiences to the model after we controlled for the contextual variables, and perceived racial discrimination was associated with 1.90 times higher odds of mental distress. Finally, in Model 3, we added the interaction terms of perceived racial discrimination with each of the contextual variables, and the terms with statistical significance are presented in Model 3A, 3B, and 3C. Interaction terms with age 60 or older (odds ratio [OR] 1.17, 95\% confidence interval [CI] [1.02, 1.35]), education (OR 1.16, 95\% CI [1.01, 1.33]), and being Vietnamese (OR 1.18, 95\% CI [1.02, 1.37]) were statistically significant.

To facilitate the interpretation, we stratified the sample by statistically significant moderating factors. The influence of perceived racial discrimination on mental distress was stronger for those who were 60 or older (OR 3.29, 95\% CI $[1.94,5.59])$ than it was in the reference group of younger adults (OR 1.63, 95\% CI [1.23, 2.17]). Similarly, racial discrimination had more negative impacts on study participants with less than 12 years of education (OR 3.30, 95\% $\mathrm{CI}[1.95,5.59])$ than its impacts among counterparts with 12 or more years of education (OR 1.72, 95\% CI [1.38, 2.15]). Finally, the Vietnamese group was more prone to mental distress associated with racial discrimination (OR 2.88, 95\% CI $[1.79,4.65])$ than were the Chinese group (OR 1.38, 95\% CI $[.93,2.06])$. The subgroup differences are visualized in Fig. 1.

\section{Discussion}

Using diverse ethnic groups of Asian Americans, this study sought to assess the degree to which the experience of racial discrimination is related to mental health and how this relationship varies by demographic, health-related, and immigration-related contextual characteristics. Our findings show that almost a third of the sample reported perceived racial discrimination, and this prevalence is in the range reported by other studies of Asian Americans [2]. Our sample also demonstrated a high incidence of mental health problems. The prevalence of mental distress $(\mathrm{K} 6 \geq 6)$ in the overall sample (44.2\%) is notably higher than the $15 \%$ reported in national samples of the U.S. general population [22]. With prevalence of $54.6 \%$, the Vietnamese respondents in this study were the most vulnerable to mental distress.

In accordance with the literature suggesting perceived discrimination as a major life stressor $[4,16]$, we did confirm the close link between perceived racial discrimination and mental distress in the present sample of Asian Americans. In addition to the direct effect, our findings also demonstrated the moderating function of the contextual factors; 
Table 1 Descriptive characteristics of the sample

\begin{tabular}{|c|c|c|c|c|c|c|c|c|}
\hline & \multicolumn{7}{|l|}{$\%$} & \multirow[t]{2}{*}{$\chi^{2}$} \\
\hline & $\begin{array}{l}\text { Total Sample } \\
(\mathrm{n}=2609)\end{array}$ & $\begin{array}{l}\text { Chinese } \\
(n=640)\end{array}$ & $\begin{array}{l}\text { Asian Indian } \\
(\mathrm{n}=574)\end{array}$ & $\begin{array}{l}\text { Korean } \\
(\mathrm{n}=471)\end{array}$ & $\begin{array}{l}\text { Vietnamese } \\
(\mathrm{n}=513)\end{array}$ & $\begin{array}{l}\text { Filipino } \\
(\mathrm{n}=265)\end{array}$ & $\begin{array}{l}\text { Other Asian } \\
(\mathrm{n}=146)\end{array}$ & \\
\hline \multicolumn{9}{|l|}{ Age } \\
\hline $18-39$ & 48.3 & 47.0 & 68.6 & 38.9 & 39.0 & 42.2 & 47.9 & \multirow[t]{3}{*}{$176.1 * * *$} \\
\hline $40-59$ & 31.2 & 27.7 & 14.3 & 40.2 & 38.6 & 41.4 & 39.7 & \\
\hline $60+$ & 20.5 & 25.3 & 17.1 & 20.9 & 22.4 & 16.3 & 12.3 & \\
\hline \multicolumn{9}{|l|}{ Gender } \\
\hline Male & 44.8 & 43.0 & 60.1 & 39.5 & 42.5 & 30.0 & 45.2 & \multirow[t]{2}{*}{$84.3 * * *$} \\
\hline Female & 55.2 & 57.0 & 39.9 & 60.5 & 57.5 & 70.0 & 54.8 & \\
\hline \multicolumn{9}{|l|}{ Marital status } \\
\hline Married & 66.6 & 63.7 & 74.8 & 74.3 & 58.3 & 59.7 & 63.4 & \multirow[t]{2}{*}{$54.3 * * *$} \\
\hline Not married & 33.4 & 36.3 & 25.2 & 25.7 & 41.7 & 40.3 & 36.6 & \\
\hline \multicolumn{9}{|l|}{ Education } \\
\hline$>12$ years & 81.4 & 85.8 & 92.4 & 79.7 & 63.7 & 83.8 & 80.0 & \multirow[t]{2}{*}{$159.2 * * *$} \\
\hline$\leq 12$ years & 18.6 & 14.2 & 7.6 & 20.3 & 36.3 & 16.2 & 20.0 & \\
\hline \multicolumn{9}{|c|}{ Chronic medical condition } \\
\hline None & 71.6 & 71.4 & 74.9 & 72.3 & 67.4 & 66.9 & 80.4 & \multirow[t]{3}{*}{$21.1^{*}$} \\
\hline One & 18.8 & 19.0 & 17.0 & 18.2 & 22.0 & 19.2 & 16.1 & \\
\hline Two or more & 9.5 & 9.6 & 8.1 & 9.5 & 10.6 & 13.8 & 3.5 & \\
\hline \multicolumn{9}{|c|}{ Length of stay in the U.S. } \\
\hline$\geq 10$ years & 58.3 & 59.0 & 34.0 & 62.8 & 74.0 & 69.2 & 62.1 & \multirow[t]{2}{*}{$206.3 * * *$} \\
\hline$<10$ years & 41.7 & 41.0 & 66.0 & 37.2 & 26.0 & 30.8 & 37.9 & \\
\hline \multicolumn{9}{|c|}{ English proficiency } \\
\hline Proficient & 37.6 & 28.3 & 55.2 & 20.8 & 27.1 & 65.0 & 50.7 & \multirow[t]{2}{*}{$274.7 * * *$} \\
\hline Limited & 62.4 & 71.7 & 44.8 & 79.2 & 72.9 & 35.0 & 49.3 & \\
\hline \multicolumn{9}{|l|}{ Acculturation } \\
\hline High & 67.3 & 54.7 & 64.0 & 65.8 & 75.4 & 88.9 & 72.4 & \multirow[t]{2}{*}{$121.1 * * *$} \\
\hline Low & 32.7 & 45.3 & 36.0 & 34.2 & 24.6 & 11.1 & 27.6 & \\
\hline \multicolumn{9}{|c|}{ Perceived discrimination } \\
\hline No & 69.7 & 66.0 & 81.1 & 63.6 & 67.6 & 71.5 & 65.0 & \multirow[t]{2}{*}{$44.8^{* * *}$} \\
\hline Yes & 30.3 & 34.0 & 18.9 & 36.4 & 32.4 & 28.5 & 35.0 & \\
\hline \multicolumn{9}{|l|}{ Mental distress } \\
\hline No $($ K6 <6) & 55.8 & 61.1 & 59.0 & 56.2 & 45.4 & 58.4 & 51.1 & \multirow[t]{2}{*}{$33.2 * * *$} \\
\hline Yes $(K 6 \geq 6)$ & 44.2 & 38.9 & 41.0 & 43.8 & 54.6 & 41.6 & 48.9 & \\
\hline
\end{tabular}

$* p<.05 ; * * * p<.001$

the adverse mental health consequences of perceived racial discrimination were stronger for older adults, individuals with low education levels, and Vietnamese Americans when compared with their respective reference groups. These findings add to existing literature by identifying subgroups of Asian Americans who might be at a particularly high risk for mental distress related to perceived racial discrimination.

Multiple factors could account for the observed group differences from the contextual factors. Moving beyond the previous research suggesting age and education as source of discrimination [9], we found that they served as conditioning factors that alleviated or intensified the impact of perceived racial discrimination. The characteristics associated with advanced age and low education, such as language barriers, low social and financial status, and restricted social network may diminish individuals' coping resources and heighten mental health risks [23-25]. Given that contextual factors are closely linked to the ability to develop necessary means and cope with life stressors, individuals with social disadvantages might be prone to the proliferating effects of stresses and mental health challenges [16].

The findings on Vietnamese Americans are noteworthy. They not only had the highest prevalence of mental distress in this study (54.6\%) but also demonstrated greater impacts from perceived discrimination than the Chinese group. These findings need to be considered in the historical and 
Table 2 Logistic regression models of mental distress

\begin{tabular}{|c|c|c|c|c|c|}
\hline & \multicolumn{5}{|c|}{ Odds ratio ( $95 \%$ confidence interval) } \\
\hline & Model 1 & Model 2 & Model 3A & Model 3B & Model 3C \\
\hline \multicolumn{6}{|l|}{ Age (ref: 18-39) } \\
\hline $40-59$ & $.53 * * *(.41, .67)$ & $.53 * * *(.42, .68)$ & $.55 * * *(.42, .71)$ & $.54 * * *(.42, .69)$ & $.54 * * *(.42, .69)$ \\
\hline $60+$ & $.24 * * *(.17, .34)$ & $.26^{* * *}(.18, .36)$ & $.29 * * *(.20, .41)$ & $.26 * * *(.18, .36)$ & $.25 * * *(.18, .35)$ \\
\hline \multicolumn{6}{|l|}{ Gender (ref: male) } \\
\hline Female & $1.20(1.00,1.45)$ & $1.19(.99,1.44)$ & $1.21(1.00,1.46)$ & $1.20(.99,1.45)$ & $1.19(.99,1.44)$ \\
\hline \multicolumn{6}{|l|}{$\begin{array}{l}\text { Marital status (ref: } \\
\text { married) }\end{array}$} \\
\hline Not married & $1.90 * * *(1.54,2.34)$ & $1.88 * * *(1.52,2.32)$ & $1.90 * * *(1.54,2.35)$ & $1.89 * * *(1.53,2.33)$ & $1.90 * * *(1.54,2.35)$ \\
\hline \multicolumn{6}{|l|}{$\begin{array}{l}\text { Education } \\
\text { (ref: }>12 \text { years) }\end{array}$} \\
\hline$\leq 12$ years & $1.03(.80,1.34)$ & $1.07(.82,1.39)$ & $1.08(.83,1.40)$ & $1.21(.91,1.62)$ & $1.10(.85,1.43)$ \\
\hline \multicolumn{6}{|l|}{$\begin{array}{l}\text { Ethnicity (ref: Chi- } \\
\text { nese) }\end{array}$} \\
\hline Asian Indian & $1.16(.87,1.55)$ & $1.29(.96,1.72)$ & $1.30(.97,1.74)$ & $1.28(.96,1.72)$ & $1.24(.90,1.72)$ \\
\hline Korean & $1.41 *(1.07,1.87)$ & $1.40 *(1.05,1.85)$ & $1.39 *(1.05,1.85)$ & $1.39 *(1.05,1.85)$ & $1.45 *(1.08,1.94)$ \\
\hline Vietnamese & $1.97 * * *(1.47,2.63)$ & $2.03 * * *(1.52,2.72)$ & $2.03 * * *(1.51,2.72)$ & $2.06 * * *(1.54,2.77)$ & $2.24 * * *(1.65,3.06)$ \\
\hline Filipino & $1.13(.79,1.61)$ & $1.22(.85,1.75)$ & $1.23(.86,1.77)$ & $1.22(.85,1.75)$ & $1.22(.83,1.79)$ \\
\hline Others & $1.56 *(1.02,2.39)$ & $1.58 *(1.03,2.44)$ & $1.59 *(1.04,2.46)$ & $1.61 *(1.04,2.48)$ & $1.70 *(1.08,2.68)$ \\
\hline \multicolumn{6}{|l|}{$\begin{array}{l}\text { Chronic medical con- } \\
\text { ditions (ref: none) }\end{array}$} \\
\hline One & $1.43 * *(1.11,1.85)$ & $1.40 *(1.08,1.81)$ & $1.41 *(1.09,1.82)$ & $1.40 *(1.08,1.81)$ & $1.40 *(1.08,1.81)$ \\
\hline Two or more & $2.38 * * *(1.66,3.40)$ & $2.30 * * *(1.60,3.31)$ & $2.32 * * *(1.61,3.33)$ & $2.29 * * *(1.59,3.29)$ & $2.32 * * *(1.61,3.33)$ \\
\hline \multicolumn{6}{|l|}{$\begin{array}{l}\text { Length of stay in the } \\
\text { U.S. (ref: } \geq 10 \text { years) }\end{array}$} \\
\hline$<10$ years & $1.00(.80,1.26)$ & $1.09(.86,1.37)$ & $1.08(.85,1.36)$ & $1.08(.86,1.37)$ & $1.07(.85,1.35)$ \\
\hline \multicolumn{6}{|l|}{$\begin{array}{l}\text { English proficiency } \\
\text { (ref: proficient) }\end{array}$} \\
\hline $\begin{array}{l}\text { Limited English } \\
\text { proficiency }\end{array}$ & $1.56 * * *(1.23,1.97)$ & $1.63 * * *(1.29,2.07)$ & $1.63 * * *(1.29,2.07)$ & $1.62 * * *(1.28,2.06)$ & $1.64 * * *(1.30,2.08)$ \\
\hline \multicolumn{6}{|l|}{$\begin{array}{l}\text { Acculturation (ref: } \\
\text { high) }\end{array}$} \\
\hline Low & $1.09(.88,1.36)$ & $1.10(.89,1.37)$ & $1.11(.89,1.39)$ & $1.11(.89,1.38)$ & $1.09(.88,1.36)$ \\
\hline \multicolumn{6}{|l|}{$\begin{array}{l}\text { Perceived discrimina- } \\
\text { tion (ref: no) }\end{array}$} \\
\hline Yes & & $1.90 * * *(1.56,2.33)$ & $2.42 * * *(1.78,3.28)$ & $2.32 * * *(1.76,3.06)$ & $3.39 * *(1.41,8.14)$ \\
\hline \multicolumn{6}{|l|}{$\begin{array}{l}\text { Interaction with age } \\
(\text { ref = age 18-39) }\end{array}$} \\
\hline $\begin{array}{l}\text { Discrimination } \times \text { age } \\
(40-59)\end{array}$ & & & $1.03(.93,1.16)$ & - & - \\
\hline $\begin{array}{l}\text { Discrimination } \times \text { age } \\
(60+)\end{array}$ & & & $1.17 *(1.02,1.35)$ & - & - \\
\hline \multicolumn{6}{|l|}{$\begin{array}{l}\text { Interaction with } \\
\text { education } \\
\text { (ref }=>12 \text { years })\end{array}$} \\
\hline $\begin{array}{l}\text { Discrimina- } \\
\text { tion } \times \leq 12 \text { years }\end{array}$ & & & & $1.16^{*}(1.01,1.33)$ & - \\
\hline \multicolumn{6}{|l|}{$\begin{array}{l}\text { Interaction with eth- } \\
\text { nicity (ref }=\text { Chinese) }\end{array}$} \\
\hline $\begin{array}{l}\text { Discrimina- } \\
\text { tion } \times \text { Asian Indian }\end{array}$ & & & & & $1.00(.86,1.16)$ \\
\hline $\begin{array}{l}\text { Discrimina- } \\
\text { tion } \times \text { Korean }\end{array}$ & & & & & $1.09(.94,1.26)$ \\
\hline
\end{tabular}


Table 2 (continued)

\begin{tabular}{|c|c|c|c|c|c|}
\hline & \multicolumn{5}{|c|}{ Odds ratio ( $95 \%$ confidence interval) } \\
\hline & Model 1 & Model 2 & Model 3A & Model 3B & Model 3C \\
\hline $\begin{array}{l}\text { Discrimina- } \\
\text { tion } \times \text { Vietnamese }\end{array}$ & & & & & $1.18 *(1.02,1.37)$ \\
\hline $\begin{array}{l}\text { Discrimination } \times \text { Fili- } \\
\text { pino }\end{array}$ & & & & & $1.03(.86,1.24)$ \\
\hline $\begin{array}{l}\text { Discrimina- } \\
\text { tion } \times \text { Others }\end{array}$ & & & & & $1.14(.91,1.43)$ \\
\hline Summary statistic & $\begin{array}{l}-2 \log \text { likeli- } \\
\text { hood }=2675.2 \\
\chi^{2} / \mathrm{df}=196.9^{* * * / 15}\end{array}$ & $\begin{array}{l}-2 \log \text { likeli- } \\
\text { hood }=2635.9 \\
\chi^{2} / \mathrm{df}=236.2 * * * / 16\end{array}$ & $\begin{array}{l}-2 \log \text { likeli- } \\
\text { hood }=2631.1 \\
\chi^{2} / \mathrm{df}=241.0^{* * * / 18}\end{array}$ & $\begin{array}{l}-2 \log \text { likeli- } \\
\text { hood }=2631.5 \\
\chi^{2} / \mathrm{df}=240.6^{* * * / 17}\end{array}$ & $\begin{array}{l}-2 \log \text { likeli- } \\
\text { hood }=2629.3 \\
\chi^{2} / \mathrm{df}=242.79^{* * * / 21}\end{array}$ \\
\hline
\end{tabular}

$* p<.05 ; * * p<.01 ; * * * p<.001$

Fig. 1 Odds ratios of perceived discrimination predicting mental distress in subgroups

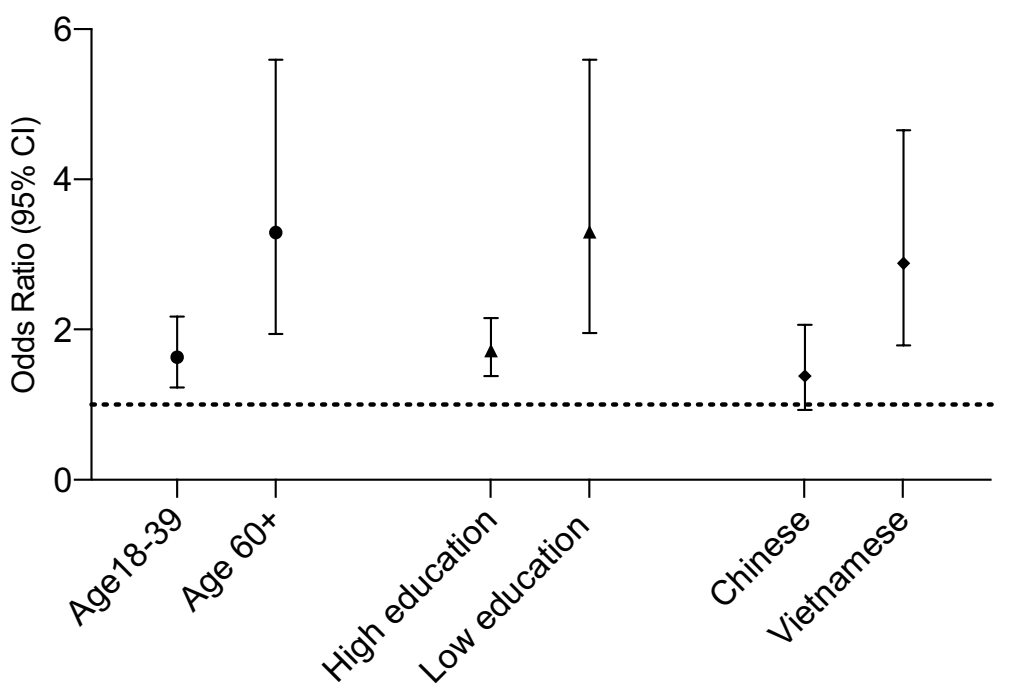

political context of Vietnamese immigrants' settlement in the United States as refugees [26]. The traumatic experiences during the war, the evacuation, and the resettlement processes are documented as having posed substantial risks to the psychosocial adaptation and mental health of Vietnamese Americans [27], and the recent experiences of racial discrimination are adding to their burden [28]. Given vulnerabilities particular to the Vietnamese population in the United States, further attention is warranted on issues related to racial discrimination and mental health in Vietnamese Americans.

Several limitations of the present study should be noted. The use of a cross-sectional design and a nonprobability sample in a geographically restricted region limited our ability to draw causal inferences and generalize the findings to a broad population. Despite the AAQoL team's effort to build a sample of Asian Americans that reflected the population's cultural and linguistic diversities, individuals from small ethnic groups and those who were disconnected from the community were underrepresented. We should also note that we only measured perceived racial discrimination with a single item. To capture the range and depth of racial discriminatory experiences, future researchers should employ multi-item scales with good psychometric properties. Similarly, investigators should measure acculturation with a validated instrument because its absence of impact in the present investigation might also have been because we used only a single-item measure. Additionally, caution is warranted in interpreting the moderating effects owing to the wide and overlapping confidence intervals.

Despite these limitations, our findings offer useful public health implications. We elucidated the diversity of the Asian American population and identified important differences by ethnic subgroups. Our focus on the moderating functions of contextual factors identified subgroups that are prone to heightened mental health risks, and these findings can guide strategic interventions by prioritizing high risk groups and suggesting targeted interventions. Our findings warrant particular attention to the contextual factors of age, education, and ethnicity, and underscore the need to take a nuanced 
approach with an intersectional lens. Because racism has impacts along systemic, institutional, cultural, and interpersonal pathways [29,30], interdisciplinary efforts are needed to develop multipronged interventions designed to eliminate racism and achieve mental health equity for diverse populations. Given the elevated anti-Asian racism during the COVID-19 pandemic [3], it is imperative to proactively respond to the racial discrimination experienced by Asian Americans and its mental health consequences.

Funding This work was funded by City of Austin (Grant No. 26-8275-39).

\section{References}

1. Sue DW, Bucceri J, Lin AI, Nadal KL, Torino GC. Racial microaggressions and the Asian American Experience. Cult Divers Ethn Minor Psychol. 2007;13(1):72-81.

2. Harvard TH. Chan School of Public Health, Robert Wood Johnson Foundation, National Public Radio: discrimination in America: experiences and views of Asian Americans. 2017. https://legacy. npr.org/assets/news/2017/12/discriminationpoll-asian-americans. pdf.

3. Lee S, Waters SF. Asians and Asian Americans' experiences of racial discrimination during the COVID-19 pandemic: impacts on health outcomes and the buffering role of social support. Stigma Health. 2021;6(1):70-8.

4. Williams DR. Stress and the mental health of populations of color: advancing our understanding of race-related stressors. J Health Soc Behav. 2018;59(4):466-85.

5. Paradise Y, Ben J, Denson N, Elias A, Priest N, Pieterse A, Gupta A, Kelaher M, Gee G. Racism as a determinant of health: a systematic review and meta-analysis. PLoS ONE. 2015;10(9):e0138511

6. Oh H, Stickley A, Koyanagi A, Yau R, DeVylder JE. Discrimination and suicidality among racial and ethnic minorities in the United States. J Affect Disord. 2019;245:517-23.

7. Lee DL, Ahn S. Racial discrimination and Asian mental health: a meta-analysis. Couns Psychol. 2011;39(3):463-89.

8. Gee GC, Ro A, Shariff-Marco S, Chae D. Racial discrimination and health among Asian Americans: evidence, assessment, and directions for future research. Epidemiol Rev. 2009;31(1):130-51.

9. Li LW, Dong X. Self-reported discrimination and depressive symptoms among older Chinese adults in Chicago. J Gerontol A. 2017;72(S1):S119-24.

10. Zhang W, Hong S, Takeuchi DT. Mossakowski: limited English proficiency and psychological distress among Latinos and Asian Americans. Soc Sci Med. 2012;75(6):1006-14.

11. Nadimpalli SB, Kanaya AM, McDade TW, Kandula NR. Selfreported discrimination and mental health among Asian Indians: cultural beliefs and coping style as moderators. Asian Am J Psychol. 2016;7(3):185-94.

12. Mossakowski KN, Zhang W. Does social support buffer the stress of discrimination and reduce psychological distress among Asian Americans? Soc Psychol Q. 2014;77(3):273-95.

13. Yip T, Gee GC, Takeuchi DT. Racial discrimination and psychological distress: the impact of ethnic identity and age among immigrant and United States-born Asian adults. Dev Psychol. 2008;44(3):787-800.
14. Zhang W, Hong S. Perceived discrimination and psychological distress among Asian Americans: does education matter? J Immigr Minor Health. 2013;15(5):932-43.

15. Budiman A, Ruiz NG. Key facts about Asian Americans, a diverse and growing population. 2021. Pew Research Center. https://www. pewresearch.org/fact-tank/2017/09/08/key-facts-about-asianamericans/.

16. Pearlin LI, Schieman S, Fazio EM, Meersman SC. Stress, health, and the life course: some conceptual perspectives. J Health Soc Behav. 2005;46(2):205-19.

17. City of Austin. Asian American quality of life. 2017. http://www. austintexas.gov/sites/default/files/files/Communications/4.2_ FINAL_AA_in_Austin_report_from_UT.pdf.

18. Kessler RC, Andrews G, Colpe LJ, Hiripi E, Mroczek DK, Normand S-LT, Walters EE, Zaslavsky AM. Short screening scales to monitor population prevalences and trends in non-specific psychological distress. Psychol Med. 2002;32(6):959-76.

19. Kessler RC, Barker PR, Colpe LJ, Epstein JF, Gfroerer JC, Hiripi E, Howes MJ, Normand S-LT, Manderscheid RW, Walters EE, Zaslavsky AM. Screening for serious mental illness in the general population. Arch Gen Psychiatry. 2003;60(2):184-9.

20. Cheung M. Elderly Chinese living in the United States: assimilation or adjustment? Soc Work. 1989;34(5):457-61.

21. Beiser M, Edwards RG. Mental health of immigrants and refugees. New Dir Ment Health Serv. 1994;61:73-86.

22. Forman-Hoffman VL, Muhuri PK, Novak SP, Pemberton MR, Ault KL, Mannix D. Psychological distress and mortality among adults in the US household population: CBHSQ Data Review 2014. https://www.samhsa.gov/data/sites/default/files/CBHSQDR-C11-MI-Mortality-2014/CBHSQ-DR-C11-MI-Mortality2014.htm.

23. Guo M, Steinberg NS, Dong X, Tiwari A. A cross-sectional study of coping resources and mental health of Chinese older adults in the United States. Aging Ment Health. 2018;22(11):1448-55.

24. Dalgard OS, Mykletun A, Rognerud M, Johansen R, Zahl PH. Education, sense of mastery and mental health: results from a nation wide health monitoring study in Norway. BMC Psychiatry. 2007. https://doi.org/10.1186/1471-244X-7-20.

25. Ross CE, Mirowsky J. The sense of personal control: social structural causes and emotional consequences. In: Aneshensel CS, Phelan JC, Bierman A, editors. Handbooks of sociology and social research. Dordrecht: Springer; 2013. p. 379-402.

26. Pew Research Center. The rise of Asian Americans. 2013. https:// www.pewresearch.org/social-trends/2012/06/19/the-rise-of-asianamericans/.

27. Birman D, Tran N. Psychological distress and adjustment of Vietnamese refugees in the United States: association with pre- and postmigration factors. Am J Orthopsychiatry. 2008;78(1):109-20.

28. Nguyen T, Cho YJ, Jang Y. Perceived discrimination, psychosocial resources, and mental distress in Vietnamese Americans. J Migr Health. 2021;3:100039.

29. Gee GC, Ford CL. Structural racism and health inequities: old issues, new directions. Du Bois Rev. 2011;8(1):115-32.

30. Harrell CJP, Burford TI, Cage BN, Nelson TM, Shearon S, Thompson A, Green S. Multiple pathways linking racism to health outcomes. Du Bois Rev. 2011;8(1):143-215.

Publisher's Note Springer Nature remains neutral with regard to jurisdictional claims in published maps and institutional affiliations. 